\title{
Development of Smart Helmet Motor Cycles' Embedded System
}

\author{
Phesto Peter Namayala \\ Department of Information and Communication Technology \\ Mbeya University of Science and Technology \\ Box 131, Mbeya, Tanzania.
}

\begin{abstract}
In Tanzania, motorcycles taxi has emerged as the key mode of transport for both rural and urban areas. The numbers of motorcycles and motorized tricycles in Tanzania has increased rapidly in recent years, changing the face of accessibility and mobility. Motorcycles provide employment and business opportunities for tens and thousands of people. However, the increase of motorcycles causes the increases in fatal accidents which takes the lives of much younger one and leave many others crippled. The governments of Tanzania and other stakeholders have been intervening for the purpose of reducing fatal accidents though instituted efforts have not been able to solve the problem. Among others consuming excessive alcohols and not wearing helmets have been the major causes of fatal accidents and injuries.

This research aim at solving the problem by preventing riders accessing the motorcycle when they are either drunk or have not worn the helmet, the research develops a prototype which automatically prevents the motorcycle from starting when any of the two requirements are not met.

A sample of eighty(80) respondents was visited using a structured questionnaire using simple random sampling technique, to present findings data were analyzed used an IBM SPSS software.
\end{abstract}

Key Words: Embedded System, Motorcycle, Smart helmet, Accidents, Tanzania .

\section{INTRODUCTION}

\subsection{Background study}

As the recent inclination in Tanzania, motorcycles taxi has emerged as the key mode of transport for both rural and urban areas. The numbers of motorcycles and motorized tricycles in Tanzania has increased rapidly in recent years, changing the face of accessibility and mobility. In urban areas, both motorcycles and motorized tricycles are used to avoid congestion, often as taxis, and in rural areas motorcycles are often the only form of motorized transport available. They provide employment and business opportunities for tens and thousands of people [1]. However, the number of motorcycles and tricycles accidents which causes death and injuries increases every year as tricycles operating in the country has increased. Motorcycle injuries are among the leading causes of disability and deaths and the main victims are the motorcyclists, passengers and pedestrians in their young reproductive age group. There has been interventions of governments and other stakeholders for ensuring the safety of motorbike riders, among others training on road safety, encourage the formation of associations of motorcycles and tricycles drivers, empowering associations to self-regulate and conducting special roads operations have been widely implemented. However the interventions have neither reduced the number of fatal accidents nor injuries on accidents which raises an alarm for more sophisticated interventions.

Smart helmet is a type of protective headgear used by the rider which makes bike driving safer than before. The main purpose of this smart helmet is to provide safety for rider. This is implemented by using advance features like alcohol detection, accident identification, location tracking, use as a hands-free device, solar powered, fall detection. This makes not only smart helmet but also feature of smart bike. Its compulsory to wear helmet, without helmet ignition switch cannot be turned ON. A RF Module as wireless link which is able to communicate between transmitter and receiver. If rider is drunk ignition switch is automatically locked. [2] 
The idea of this research comes from social responsibility towards the society. Bike riding is a lot of fun, but accidents happen. People choose motorbikes over car as it is much cheaper to run, easier to repair, easier to park and flexible in traffic. In India more than 37 million people are using two wheelers. Since usage is high accident percentage of two wheelers are also high compared to four wheelers. Motorcycles have high rate of fatal accidents than cars or trucks and buses.

This research aims at accident causalities avoidance. The main purpose of the research is to encourage wearing of helmet. The developed system will ensure that the motorbike will not start unless the rider is wearing a helmet and has not consumed an alcohol. Thus, alcohol detection is also an important part in this research. Alcohol detection is done by MQ-3 sensor and helmet detection is done by IR and PIR sensors [3]

\section{2: Problem Statement}

The number of motorcycle accidents increase every year. In Tanzania a total of 23,842 and 14,360 accidents, fatality and injury occurred between 2013 and 2014 respectively. The deaths between the mentioned periods were 4,002 and 3,760 respectively. A total of 20,689 and 14,530 of injuries occurred between 2013 and 2014 respectively In 2015, the police region with the largest number of motorcycle accidents was Temeke (564) followed by Ilala (450), Ruvuma (182), Morogoro (156), Pwani (153) and Mjini Magharibi (65) [4]

Most of the rider do not wear helmet during driving. The people who are affected by motorcycle accidents are mostly in their most productive years (15-44 years). These deaths are a huge drain on the country's human resources. Also, when a head of household dies or is seriously injured in a road traffic accident, the whole family is plunged into poverty and psychological torture. Motorcycle accidents are, therefore, a big problem to the government and the society of Tanzania [5] .Haonga (2010) stated that $52 \%$ of all the patients who came to Muhimbili National hospital were road accident victims who were either injured or got dead due to motorcycle accidents; most of them being young men. [6]

Andrews (2009) appealed Alcohol and other substances have found to be major risk factors in all types of motor vehicle crashes according to the traffic safety facts, the rate of road traffic accidents associated with commercial motorcycling has also been on the increase with a rise in the number of injuries presented at hospitals. Despite the efforts made by the government to reduce road accidents involving motorcycles through training provide in the safety week, there is no empirical evidence on the assessment of the effectiveness of motorcyclist training program in reducing road accident [7]. Traffic capture manually person who don't wear helmet as initiatives of reduce injuries and death associated with the act of not wearing helmets.

This research strives on developing a smart helmet motorcycle's embedded system that automatically recognize rider's helmet wearing status and rider's alcohol intake position. When these two conditions are checked and met then the motorcycle will be able to start. If either of the condition is not met the rider will not be able to start the motorcycle. Ultrasonic sensors have been used to determine wearing status and MQ-7 sensor has been used for detecting alcohol position. Collected signals are then transmitted and received by the receiver where microcontroller interpret them and make decisions.

\section{0: RESEARCH LITERATURE REVIEW, SIGNIFICANCE AND OBJECTIVES}

\subsection{Literature Review}

In this research of developing smart helmet motorcycles' embedded system the development is cantered by the microcontroller which receives data from both ultrasonic sensor and alcohol sensor then sends to RF modules which transmit information to the motorcycle part so that it can allow relay switch open and close.

In recent times helmets have been made compulsory in Maharashtra State. Traffic accidents in India have increased year by year. As per Section129 of Motor Vehicles Act, 1988 makes it required for every single riding a two-wheeler to wear protective headgear following to standards of the BIS (Bureau of Indian Standards). In India drunken driver case is a criminal offence of The Motor Vehicle act 1939. Which states that the bike rider will get punish. In existence bike rider easily get escaped from law. When biker wears the helmet, the limit switch attached with the helmet gets pressed and a signal is generated. At the same time, through the MQ3 gas sensor it is checked that whether the biker is consuming alcohol or not. If the biker has consumed alcohol then the bike never turns on. But if he doesn't consume alcohol, then a combination of these signals is passed to the microcontroller [8]

RF Communication circuit, Helmet unit and Bike unit are connected by wireless link of RF. RF communication circuit contains encoder and decoder circuit. Encoder is on helmet side which is using to convert parallel data into serial data. The encoder is capable of encoding massage which contains of $12 \mathrm{~N}$ data bits and $\mathrm{N}$ address bits. Each address/data can stay set to with two logical states. The oscillator frequency is selected by Rosc. We choose oscillator frequency is $3 \mathrm{kHz}$, with Rosc of $1 \mathrm{M}$ ohms. 
Minimum transmission of data is 4 words. Decoder is on bike side, it used to decode serial data. It converts this serial data in to parallel. The decoders are capable to receive data that are spread by an encoder and understand it. The first bits period use as addresses and last $12 \mathrm{~N}$ bits as our desired data, where $\mathrm{N}$ is stands for address number. In this decoder circuit oscillator frequency is 50 times greater than fOSCE (encoder oscillator frequency). fOSCD is $150 \mathrm{kHz}$, which is select by value of Rosc. Rosc is $1 \mathrm{k}$ ohms. [9]

Reviewed literature indicates that there are efforts going on out there in developing smart helmets for the purpose of reducing motorcycles' fatal accidents. In 2015 International Conference on Smart Sensors and Systems (IC-SSS) Muthiah et all presented a prototype of smart element for Automatic Control of Headlamps in motorcycles.

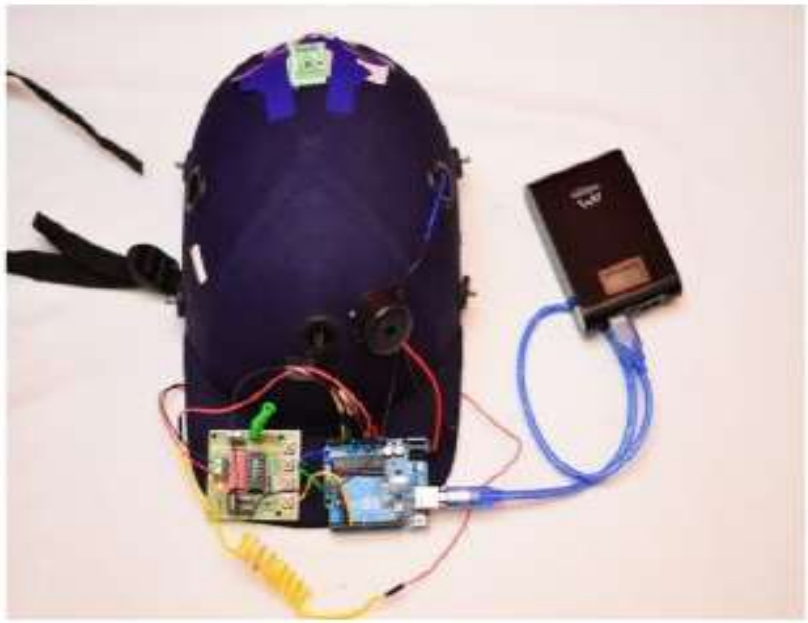

Figure 1: Front View of Muthiah et all smart helmet

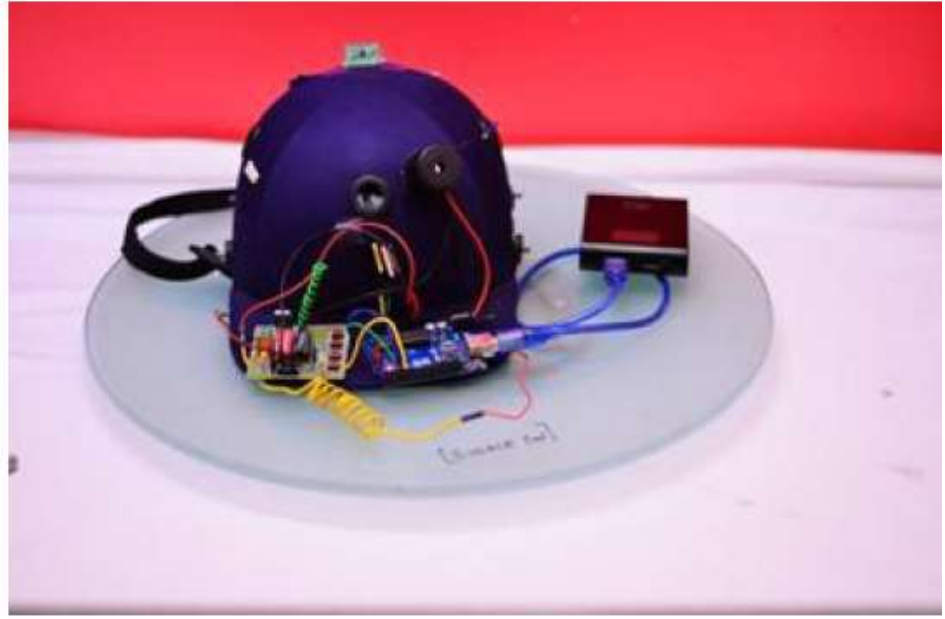

Figure 2:Top view of Muthiah et all smart helmet

However, little or nothing has been done in Tanzania; this initiative is a result of the research we conducted at Mbeya region in Iyunga ward. The research discovered the absence of formal system that is used for the purpose of reducing motorcycles' fatal accidents. Distribution table below shows responses from motorcycle riders

Table 1: How long have you been riding the motorcycle?

\begin{tabular}{|c|c|c|c|c|c|}
\hline & & Frequency & Percent & Valid Percent & Cumulative Percent \\
\hline \multirow[t]{3}{*}{ Valid } & 0-1year & 22 & 27.5 & 27.5 & 27.5 \\
\hline & 2years and more & 58 & 72.5 & 72.5 & 100.0 \\
\hline & Total & 80 & 100.0 & 100.0 & \\
\hline
\end{tabular}


International Journal of Engineering Research And Advanced Technology, Vol.5, Issue 7, July-2019

Table 2: Have you been involved in an accident?

\begin{tabular}{|c|c|c|c|c|c|}
\hline & & Frequency & Percent & Valid Percent & Cumulative Percent \\
\hline \multirow[t]{4}{*}{ Valid } & YES & 59 & 73.8 & 73.8 & 73.8 \\
\hline & NO & 19 & 23.8 & 23.8 & 97 \\
\hline & 11 & 2 & 2.5 & 2.5 & 100 \\
\hline & Total & 80 & 100.0 & 100.0 & \\
\hline
\end{tabular}

Table 3: What is the reason of motorcycle accident?

\begin{tabular}{|c|c|c|c|c|c|}
\hline & & Frequency & Percent & Valid Percent & Cumulative Percent \\
\hline \multirow[t]{4}{*}{ Valid } & Use of alcohol & 43 & 53.8 & 53.8 & 53.8 \\
\hline & $\begin{array}{l}\text { don't have good training on driving } \\
\text { motorcycles }\end{array}$ & 25 & 31.2 & 31.2 & 85.0 \\
\hline & $\begin{array}{l}\text { Car drivers are not carefully with } \\
\text { motorcyclist }\end{array}$ & 12 & 15.0 & 15.0 & 100.0 \\
\hline & Total & 80 & 100.0 & 100.0 & \\
\hline
\end{tabular}

Table 4: How do you reduce motorcycle fatal accidents?

\begin{tabular}{|c|c|c|c|c|c|}
\hline & & Frequency & Percent & Valid Percent & Cumulative Percent \\
\hline \multirow[t]{4}{*}{ Valid } & learning on the driving of bodaboda & 34 & 42.5 & 42.5 & 42.5 \\
\hline & $\begin{array}{l}\text { Forbidding anyone who drink } \\
\text { alcohol should not drive Motorcycle }\end{array}$ & 26 & 32.5 & 32.5 & 75.0 \\
\hline & I don't know & 20 & 25.0 & 25.0 & 100.0 \\
\hline & Total & 80 & 100.0 & 100.0 & \\
\hline
\end{tabular}

Table 5: How do you identify drunken riders?

\begin{tabular}{|l|r|r|r|r|}
\hline & Frequency & Percent & Valid Percent & Cumulative Percent \\
\hline Valid by looking & 50 & 62.5 & 62.5 & 62.5 \\
\hline
\end{tabular}




\begin{tabular}{|l|r|r|r|r|}
\hline To feel & 17 & 21.2 & 21.2 & 83.8 \\
Gas detector device & 13 & 16.2 & 16.2 & 100.0 \\
\hline Total & 80 & 100.0 & 100.0 & \\
\hline
\end{tabular}

Table 6: What do you ensure the riders and passengers wear helmet?

\begin{tabular}{|c|c|c|c|c|c|}
\hline & & Frequency & Percent & Valid Percent & Cumulative Percent \\
\hline \multirow[t]{4}{*}{ Valid } & $\begin{array}{l}\text { make sure they are wearing before } \\
\text { living }\end{array}$ & 29 & 36.2 & 36.2 & 36.2 \\
\hline & No way & 24 & 30.0 & 30.0 & 66.2 \\
\hline & Don't know & 27 & 33.8 & 33.8 & 100.0 \\
\hline & Total & 80 & 100.0 & 100.0 & \\
\hline
\end{tabular}

\section{2: Significance of the Research}

This research is aiming at reducing fatal motorcyclist accidents as a result of not observing road Safety; it has been observed many motorcycles' fatal accidents are a result of drunken riders. The research strives on developing a sophisticated helmet; the helmet denies the access of motorcycles' to drunken riders. The system raises discipline amongst riders which in turn implicates to fat accidents reductions, the helmet also ensures head safety to victims as their heads are protected by helmets. Helmets have proved to improve the chance of surviving road accidents.

\section{3: RESEARCH OBJECTIVES}

\subsection{1: Main Objective}

The main objective of the project is to develop the Smart Helmet motorcycles' embedded system

\subsection{2: Specific Objective}
i. To design system circuit
ii. To simulate the circuit
iii. To Interface ultrasonic sensors with the Micro-Controller Unit.
iv. To interface MQ-7 sensor with the Micro-Controller Unit
v. To Program the Micro-controllers
vi. To Test the Prototype
vii. To write documentations

\subsection{Scope and Limitation of The Research}

The scope of the research is to come up with a running prototype. 


\subsection{METHODOLOGY}

To complete this research the quantitative design approach was used, simple random sampling technique was opted and this is because the nature of the information gathered and nature of respondent involved in research. Furthermore, in data collection questionnaire with a closed ended question was used and SPSS was used as the data analysis software

\section{1 system design}

To design and in explain the structure of the system, block diagram has been opted instead of class diagram, to explain systems interactions with the actors a use case diagram has been used and to portray behavior of the system Sequence diagram has been used

\subsubsection{Block diagram of the project}

This is a graphical language explaining about the structure of the system from the input to the output as well as the functions of the particular system.

This system has two parts which are

i. Helmet part

ii. Motorcycle part

BLOCK DIAGRAM OF HELMET PART

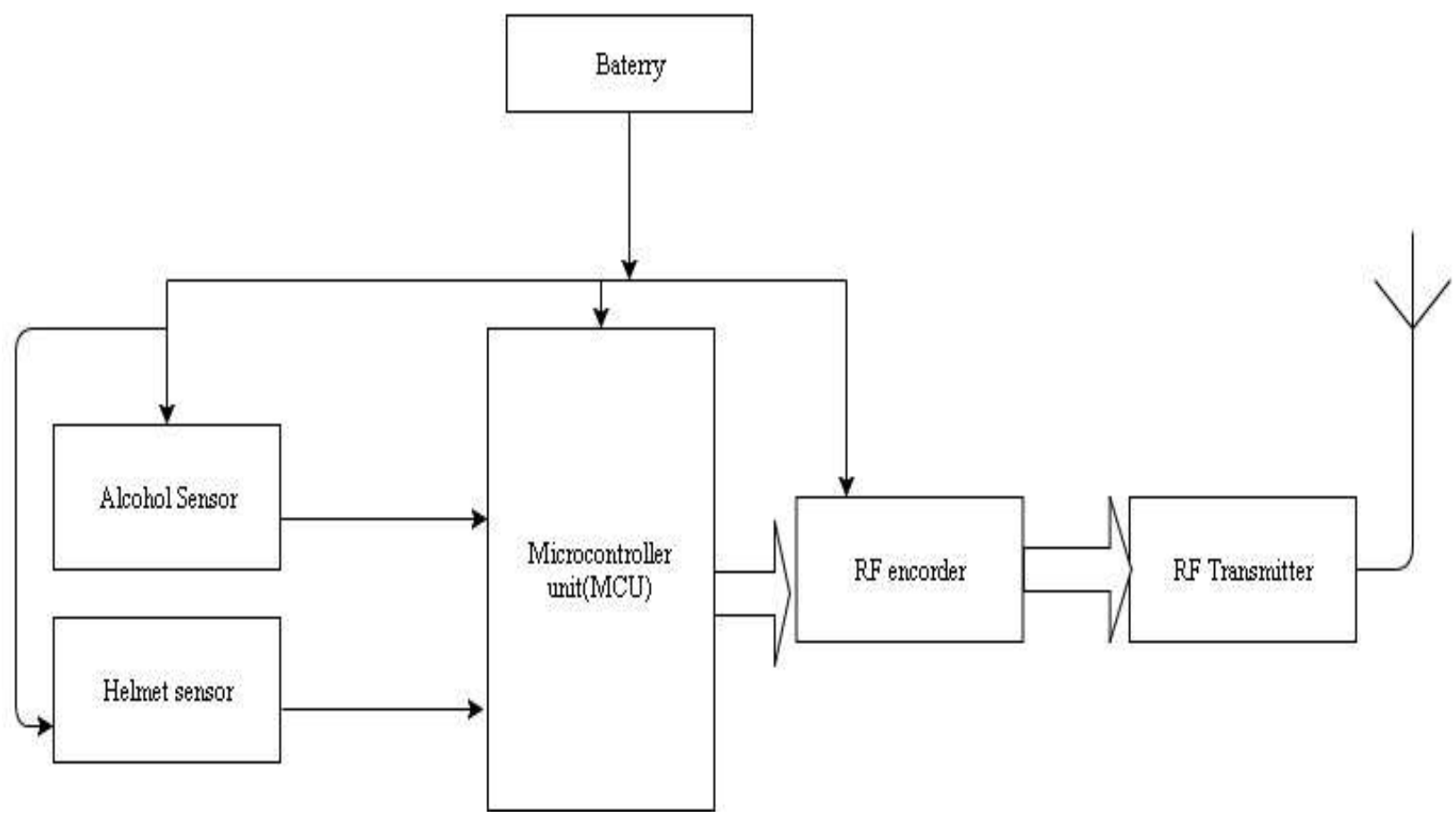

Figure 3: Helmet sub-system block diagram 


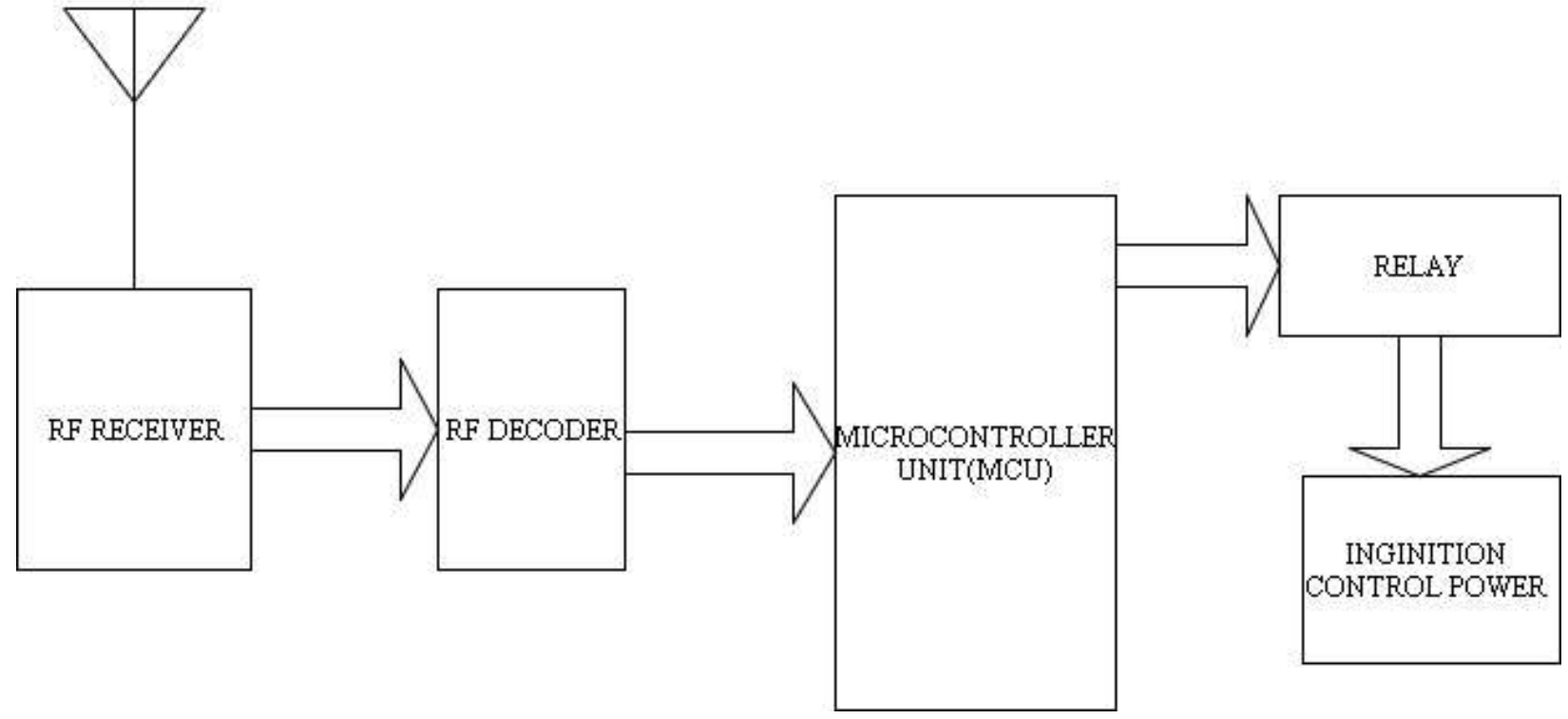

Figure 4: Motorcycle system block diagram

\subsubsection{Use case diagram}

These kinds of diagram explain about the interaction of system with external entities, use case diagrams are used to explain how these parts communicate. Figure 5 below shows the use case diagram of the smart helmet motorcycle's embedded system.

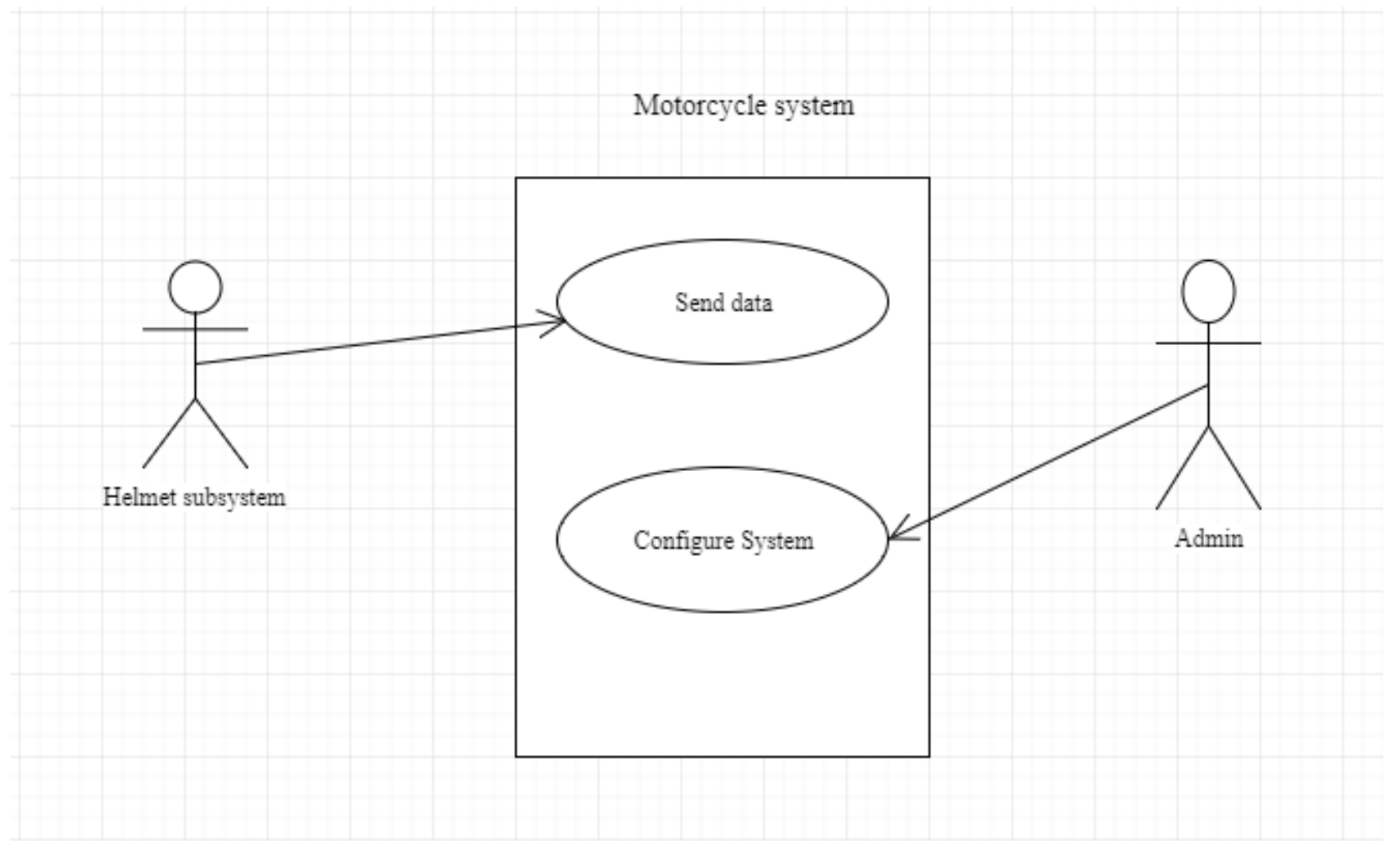

Figure 5: Use case diagram for a system 


\subsubsection{Sequence diagram}

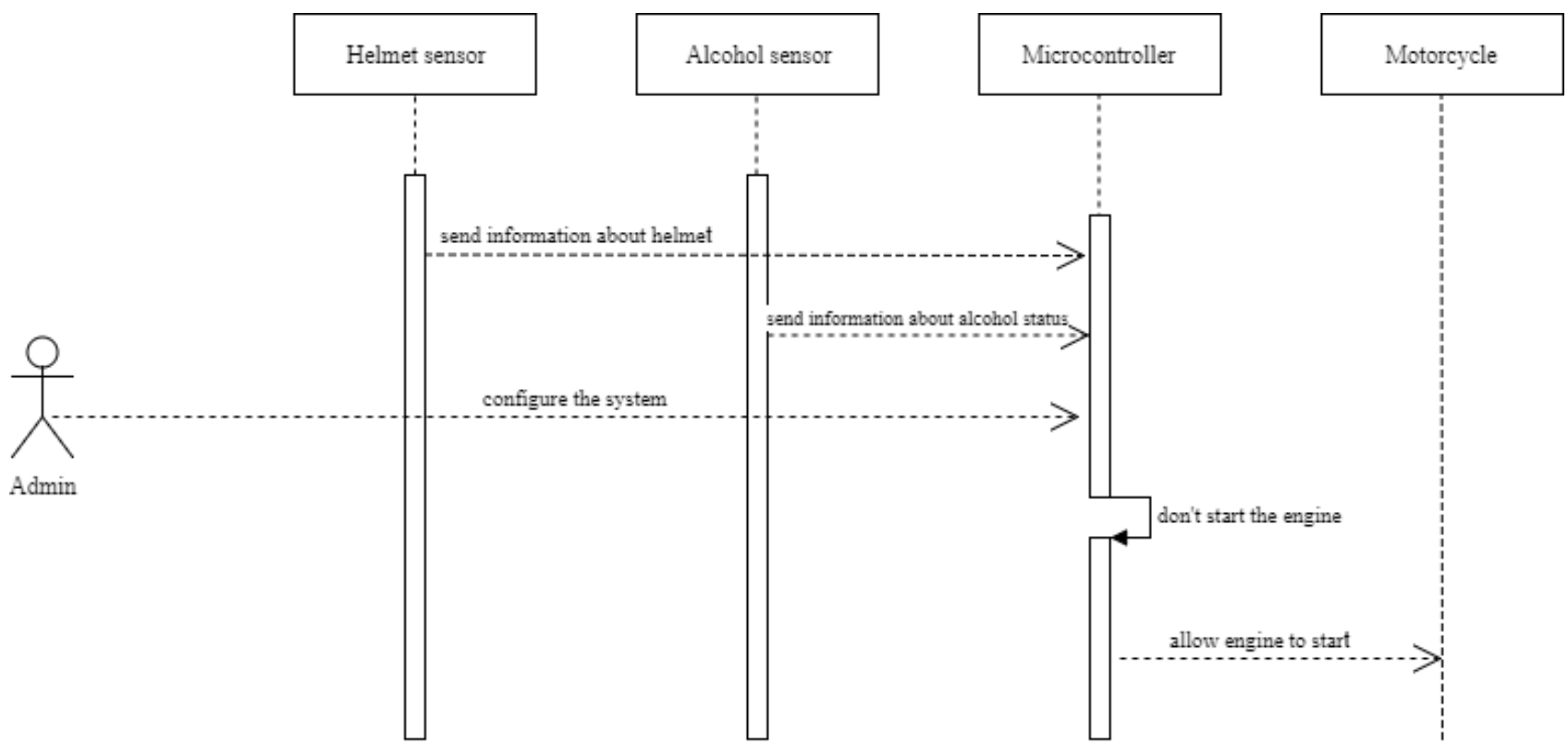

Figure 6: System's sequence diagram

\section{0: Prototyping designing}

In Prototype Designing all the required Components are gathered together. These Components are well arranged on the circuit board then soldered. Soldering is very common in every Electronic work. Soldering is the act of using a Soldering Iron together with Soldering Wire to Join Electronic Components on the Vero Board or PCB.

Soldering will be done for two different Circuits, transmitter Circuit and Receiver Circuit. Transmitter Circuit will be the circuit that receives inputs form sensors in the helmet and give out Power Activation Command Wirelessly to the Motor Cycle Power Controller. And the Receiver is the one that receives wireless command form the helmet and respond accordingly.

The Circuit in the helmet will be uses a small 9Volts Battery Supply where as that of receiver part uses the power form motor Cycle battery. After Soldering is done all the two circuits are connected to power and then tested for functionality.

Tests are taken. If the output results are contrary to what where expected trouble shouting is done to fix all the malfunctioning parts of the design and tests are taken again and again to point where the desired outputs are met.

When the output results are what where expected the two circuits are cased and housed to avoid any damage to them associated with physical contact. Then tests are taken again after the two circuits are well cased. After all the processes are carefully done system is now ready for use.

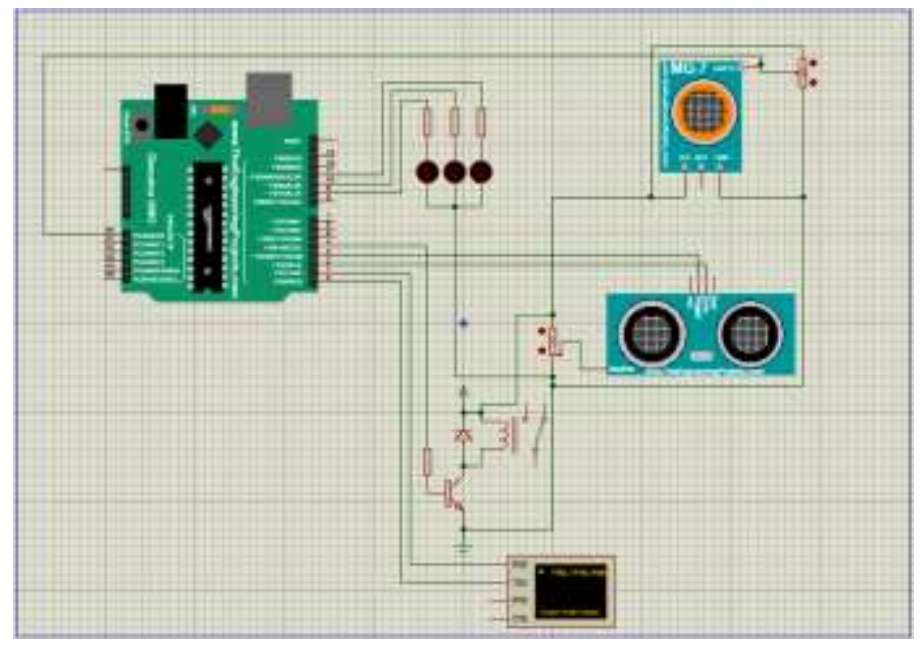

Figure 7: System's circuit for simulation 


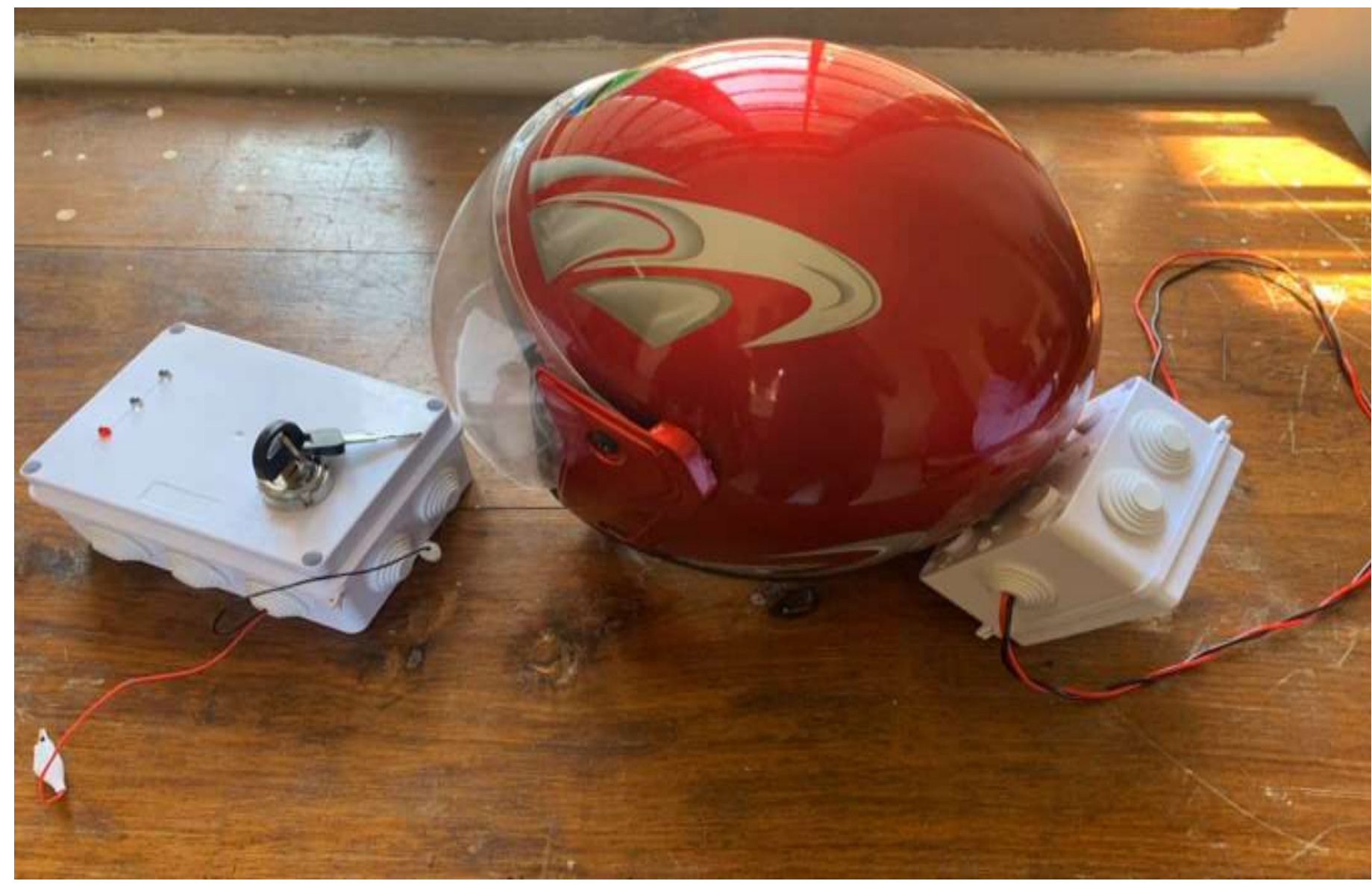

Figure 8: Developed prototype

\subsection{FINDINGS}

As the results from the analysis software most of the individuals don't have good means of reducing fatal accidents. They use their own ability to make sure they don't get into accidents. $53.8 \%$ of riders reported to use alcohol while riding, and few riders have attitude of wearing helmet, many demanded this system as a means of reminding them the importance of helmet and the risk of drinking an alcohol while riding.

\subsection{CONCLUSIONS AND RECOMMENDATIONS}

\subsection{Conclusions}

Generally, the smart helmet system makes the driver safer than before and will help to reduce motorcycle fatal accidents which are caused by the drunken motorcyclists. People who are mostly affected by motorcycle accidents are in productive years (15-44 years). These deaths are a huge drain on the country's human resources capital. By implementing mandatory Helmet protection and detection of alcohol content during the starting on the bike will consequently save precious life of numerous people.

\subsection{Recommendations}

The proposed approach makes it mandatory for the rider to use this protective guard in order to drive a motorcycle and ensures the safety of the human brain and therefore reduce the risk of brain injuries and death in case of an accident. I would recommend this smart helmet system technology to be further enhanced, the Government is encouraged to proceed with more researches in this area add more features and develop a fully functional system.

\section{Acknowledgement}

The author of this research paper acknowledges supports received from the management of the department of Information and Communication Technology, College of Engineering and Technology of Mbeya University of Science and Technology and other comments from reviewers. 


\section{REFERENCES}

[1] T. Bishop and P. Amos, "Opportunities to improve road safety through 'boda- boda' associations in Tanzania," AFCAP/ASCAPProjectManagementUnit, Thame OX92AH, 2015.

[2] P. C. P.P., "Smart Helmet \& Intelligent Bike System," International Research Journal of Engineering and Technology (IRJET), p. 487, 2016.

[3] M. Bhodoria, "HELMET WITH ALCOHOL SENSOR," International Research Journal of Engineering and Technology (IRJET), p. 1783, 2016.

[4] Ernest Jumbe Mangu - IGP, "CRIME AND TRAFFIC INCIDENTS," Tanzania Police Force Headquarters, Tanzania, 2015.

[5] U. R. o. Tanzania, "Accident statistics," National Road Safety Policy, Dar-Es-Salaam, 2005.

[6] E. G.Mnzava, "THE IMPACT OF MOTORCYCLE ACCIDENTS IN TANZANIA," Master of Health System Management (MHSM), Morogoro Municicple, 2015.

[7] C. E. Kowi, "FACTORS CAUSING COMMERCIAL MOTORCYCLE," Christopher Ernest Kowi, MOROGORO, 2015.

[8] M. Bhodoria, A. K. Gupta, A. Upadhyaya, K. Kumar and E. Shroti, "HELMET WITH ALCOHOL SENSOR," International Research Journal of Engineering and Technology (IRJET), vol. 03, no. 04 | Apr-2016, p. 4, 2016.

[9] P. ChitteP.P., M. S. Akshay S, M. T. Aniruddha N and M. B. Nilesh, "Smart Helmet \& Intelligent Bike System," International Research Journal of Engineering and Technology (IRJET), vol. 03, no. 05 | May-2016, p. 5, 2016.

\section{List of abbreviations}

MQ-7 Chinese word M stands for 'sensitive' and Q is 'gas to'

IDE Integrated Development Environment

PIR Passive Infrared

IR Infrared

RF Radio frequency

IGP Inspector General of Police

GB Gigabytes

SPSS Statistical Package for Social Sciences 